\title{
Inequities in Ambulatory Care and the Relationship Between Socioeconomic Status and Respiratory Hospi- talizations: A Population-Based Study of a Canadian City
}

\author{
Aaron J. Tracbtenberg, DPbil \\ Natalia Dik, MSc \\ Dan Chateau, PbD \\ Alan Katz, MBCbB, MSc, CCFP, \\ FCFP
}

Department of Community Health Sciences, University of Manitoba, Winnipeg, Canada
Conflicts of interest: authors report none.

\section{CORRESPONDING AUTHOR}

Alan Katz, MBChB, MSc, CCFP, FCFP Manitoba Centre for Health Policy College of Medicine, Faculty of Health Sciences

Department of Community Health Sciences University of Manitoba 408-727 McDermot Ave Winnipeg, MB R3E 3P5 Canada katz@cc.umanitoba.ca

\begin{abstract}
PURPOSE Individuals of lower socioeconomic status have higher rates of hospitalization due to ambulatory care-sensitive conditions, particularly chronic obstructive pulmonary disease and asthma. We examined whether differences in patient demographics, ambulatory care use, or physician characteristics could explain this disparity in avoidable hospitalizations.
\end{abstract}

METHODS Using administrative data from the city of Winnipeg, Manitoba, Canada, we identified all adults aged 18 to 70 years with chronic obstructive pulmonary disease or asthma, grouped together as obstructive airway disease. We divided patients into census-derived income quintiles using average household income. We performed a series of multivariate logistic regression analyses to determine how the association of socioeconomic status with the risk of obstructive airway disease-related hospitalizations changed after controlling for blocks of covariates related to patient demographics (socioeconomic status, age, sex, and comorbidity), ambulatory care use (continuity influenza vaccination and specialist referral), and characteristics of the patient's usual physician (eg, payment mechanism, sex, years in practice).

RESULTS We included 34,741 patients with obstructive airway disease, 729 (2.1\%) of whom were hospitalized with a related diagnosis during a 2-year period. Patients having a lower income were more likely to be hospitalized than peers having the highest income, and this effect of socioeconomic status remained virtually unchanged after controlling for every other variable studied. In a fully adjusted model, patients in the lowest income quintile had approximately 3 times the odds of hospitalization relative to counterparts in the highest income quintile (odds ratio $=2.93 ; 95 \%$ confidence limits: $2.19,3.93$ ).

CONCLUSIONS In the setting of universal health care, the income-based disparity in hospitalizations for respiratory ambulatory care-sensitive conditions cannot be explained by factors directly related to the use of ambulatory services that can be measured using administrative data. Our findings suggest that we look beyond the health care system at the broader social determinants of health to reduce the number of avoidable hospitalizations among the poor.

Ann Fam Med 2014;12:402-407. doi: 10.1370/afm.1683.

\section{INTRODUCTION}

A mbulatory care-sensitive conditions (ACSCs) are those medical conditions for which some hospitalization is thought to be avoidable with successful management in the community, including access to effective primary care. ${ }^{1,2}$ Hospitalizations due to these conditions continue to represent a considerable use of health care resources, however. In 2006-2007, 1 of every 8 medical hospitalizations in Canada was attributable to a subset of 7 ACSCs: chronic obstructive pulmonary disease (COPD), asthma, angina, heart failure, diabetes, hypertension, and epilepsy. Notably, more than $40 \%$ of these hospitalizations were due to COPD and asthma. ${ }^{3}$ Minimizing the number of these preventable hospitalizations could lead to considerable reductions in health care costs. ${ }^{4,5}$ 
There is a well-established link between ACSCs and socioeconomic status (SES); individuals living in low-income areas are hospitalized for these conditions more often than their high-income counterparts. This disparity has been found in the United States, ${ }^{1,4-7}$ where direct financial barriers to care may play a role, but also in countries with free universal health coverage including Canada, Australia, and Italy, ${ }^{8-13}$ where there should be equal access to care regardless of income. In fact, previous work has shown that, in Canada, the higher hospitalization rates for ACSCs in patients from lowincome vs high-income neighborhoods coincide with greater use of ambulatory physician services by the former. ${ }^{11}$ In the setting of universal health care, it has therefore been suggested that ACSC hospitalization rates are not a marker of access to ambulatory care but rather of the quality of available care or other factors such as access to prescription medications. ${ }^{14}$ Physician characteristics are also often used as surrogate markers of quality as they are associated with physician performance. ${ }^{7,15}$ In addition to differences in the pattern and type of ambulatory care received, variation in the physicians who provide care to low- and high-income patients could therefore contribute to the disparity in avoidable hospitalizations. These theories remain speculative, however, as there has yet to be an attempt to control for all of these factors when studying the effect of SES on ACSCs.

The goal of this study was to tease apart the robust effect of SES on the chronic respiratory ACSCs, namely COPD and asthma, using administrative data. These 2 diagnoses were combined under the term obstructive airway disease to avoid problems in differentiating asthma from COPD based solely on administrative claims. ${ }^{16}$ Our objective was to confirm the effect of SES on hospitalizations for obstructive airway disease and to determine whether patient demographics, ambulatory care use, and physician characteristics could explain this effect. Understanding why individuals from low-income areas are predisposed to ACSC hospitalizations is a crucial step in devising policy targeted at reducing the current inequity in these avoidable hospitalizations and minimizing the associated burden of cost.

\section{METHODS}

We performed a population-based cohort study among residents of the city of Winnipeg, the capital city and major urban center of Manitoba, Canada, with a population of approximately 700,000. Administrative data housed at the Manitoba Centre for Health Policy contains anonymized records of all Manitoba residents contacts with the health care system plus basic demographic data. We used data from physician claims files, hospital discharge abstracts, the Manitoba Immunization Monitoring System, the Canadian Census, and the Physician Resource Database, which contains physicians' demographic and practice information. ${ }^{17}$ Emergency department visits were excluded from the analyses. This analysis was part of a larger study looking at primary care service delivery, which was approved by the Health Research Ethics Board at the University of Manitoba and by the Health Information and Privacy Committee of Manitoba.

To create our cohort of adult patients with obstructive airway disease, we identified all residents of Winnipeg aged 18 to 70 years as of January 1, 2006, who had at least 1 physician visit or hospitalization between that date and December 31,2008, with a diagnosis of asthma, chronic bronchitis, emphysema, or chronic airway obstruction/COPD, that is, International Classification of Diseases, 9th Revision, Clinical Modification (ICD-9-CM) codes 491, 492, 493, or 496, and International Classification of Diseases, 10th Revision, Canada (ICD-1O-CA) codes J41 through J46. We allocated census data for the city of Winnipeg to the smallest geographic unit for which all census data are disseminated (400 to 700 persons), the dissemination area. We ranked the dissemination areas from lowest to highest mean household income and divided the population of Winnipeg into 5 income quintiles. ${ }^{18}$ We assigned patients to an income quintile based on mean household income in the dissemination area containing their postal code of residence. This aggregate-level measure of income is closely related to individual-level SES. ${ }^{8}$ Patients living in personal care homes or other institutions were excluded from the study.

We ascertained obstructive airway disease-related hospitalizations in our cohort of patients during a 2-year follow-up period (January 1, 2009, to December $31,2010)$. We included hospitalizations with a diagnosis of obstructive airway disease or a diagnosis considered an acute exacerbation of this disease, including acute bronchitis, acute bronchiolitis, pneumonia, or influenza (ICD-9-CM codes 466, 490, 480-488, and IICD-10-CA codes J09-J18, J20-J22, J40). For patients hospitalized at least once, we recorded the first hospitalization during the follow-up period as the index date. From this point in time, we gathered retrospective administrative data to measure numerous variables concerning the care of each patient leading up to their hospitalization. To avoid a time bias, we used the median time to first hospitalization as the index date for the analysis of nonhospitalized patients.

We recorded patient age, sex, and level of comorbidity based on the Johns Hopkins Adjusted Clinical Group Case-Mix System version 9. We counted the number of major aggregated diagnosis groups 
assigned to each patient based on 3 years of physician claims and hospitalization records before the index hospitalization or before the median time to that event, and classified their comorbidity level as low (0-1 major ADG), medium (2-3), or high ( $\geq 4)$. We counted the number of all-cause nonreferral physician visits during the same period. We identified each patient's usual physician as the one who provided care during the most visits and calculated a usual physician index (visits to this physician/total visits) as a measure of continuity of care. ${ }^{19}$ Patients with zero visits to a physician in the 3 -year period who could not be matched to a usual physician and patients matched to a usual physician not present in the Physician Resource Database (2.7\% of all patients) were excluded. We determined which patients had at least 1 ambulatory visit coded as a referral to a specialist for obstructive airway disease in the 3-year period, and which patients had received the annual influenza vaccine in the 1 year before index date.

For each patient's usual physician, we recorded that physician's sex, location of training, years of continuous practice in Manitoba, payment method, and status as a family physician or specialist. We calculated average daily patient load in the 3 years before the follow-up period as the total number of claims for ambulatory visits on each working day (a day on which at least 4 claims for these visits were submitted) divided by the number of working days.

We performed bivariate analysis using 1-way analysis of variance (ANOVA) for continuous variables and $\chi^{2}$ analysis for categorical variables with income quintile as the independent variable. Using hospitalization during the follow-up period as the outcome, we derived 4 multivariate logistic regression models sequentially adding different blocks of covariates to assess how the relationship between SES and hospitalizations changed after accounting for other factors. In model $\mathrm{A}$, the only predictor was income quintile. In model B, we added patient demographics. In model $\mathrm{C}$, we added patient demographics and ambulatory care use. In model $\mathrm{D}$, we added all variables. For each model, we determined the probability that income quintile was a significant predictor of hospitalization for obstructive airway disease and determined the odds ratios for being hospitalized in each of the 4 lower income quintiles compared with the highest. All data management, programming, and statistical analyses were performed using SAS version 9.3 (SAS Institute Inc) with a significance set at $P<.05$.

\section{RESULTS}

We identified 34,741 patients with obstructive airway disease living in Winnipeg who satisfied criteria for inclusion. Of these, 729 (2.1\%) were hospitalized with an obstructive airway disease-related diagnosis during the 2-year follow-up period, with a greater percentage of hospitalized patients in the lower-income quintiles. SES was significantly associated with every covariate we measured (Table 1). Looking at patient demographics, individuals from the lower-income quintiles were more likely to be female and have a higher level of comorbidity. Although SES was associated with age, the association did not follow a clear pattern. Concerning ambulatory care use, patients in the lowest income quintile (Q1) had the most physician visits, and the highest rates of influenza vaccination and specialist referrals, but the lowest usual physician index. For usual physician characteristics, the vast majority of patients were assigned to a fee-for-service family physician, although statistically more patients from the highest income quintile (Q5) were assigned to a specialist and more patients from Q1 were assigned to a salaried physician. Low-income patients were more likely to see male physicians, international medical graduates, physicians who had been practicing in Manitoba for fewer years, and physicians with a higher daily patient load.

Logistic regression analysis revealed SES to be a strong predictor of hospitalization across all models (Table 2). When income quintile was the only predictor (model A), the Wald $\chi^{2}$ value, a measure of effect size, was 139.5. This value decreased to $100.5,94.8$, and 83.6 in models $B, C$, and D, respectively, indicating decreasing impact; however, the effect remained highly significant at $P<.001$ for all 4 models. The odds ratios for being hospitalized in the 4 lowest income quintiles, vs the highest one, changed very little between models, with the biggest change being for the poorest group (Q1).

\section{DISCUSSION}

Using obstructive airway disease as a prototypical ACSC, we confirmed the association of SES with these potentially avoidable hospitalizations, showing an approximately 3 -fold increase in the odds of being hospitalized in the lowest income group relative to the highest, a result consistent with previous work. ${ }^{6,9}$ After controlling for patient demographics, ambulatory care use, and physician characteristics, the relationship between SES and hospitalizations remained virtually unchanged, despite previous suggestions that some of these factors may drive this association. ${ }^{19,13}$ To our knowledge, ours is the first study to show that the SES-based disparity in hospitalizations for chronic respiratory ACSCs remains after accounting for these 3 categories of covariates.

We found significant differences in patient demographics between the SES groups in our cohort, 
Table 1. Characteristics of Study Cohort

\begin{tabular}{|c|c|c|c|c|c|}
\hline \multirow[b]{2}{*}{ Characteristic } & \multicolumn{5}{|c|}{ Income Quintile ${ }^{a}$} \\
\hline & $\begin{array}{l}\text { Q1 (Lowest) } \\
\text { ( } n=7,915)\end{array}$ & $\begin{array}{c}Q 2 \\
(n=7,362)\end{array}$ & $\begin{array}{c}\text { Q3 } \\
(n=6,685)\end{array}$ & $\begin{array}{c}Q 4 \\
(n=6,679)\end{array}$ & $\begin{array}{c}\text { Q5 (Highest) } \\
(\mathrm{n}=6,100)\end{array}$ \\
\hline Hospitalized, \% & 3.6 & 2.5 & 1.7 & 1.3 & 1.0 \\
\hline \multicolumn{6}{|l|}{ Patient demographics } \\
\hline Sex, male, \% & 39.1 & 41.5 & 42.4 & 44.4 & 44.5 \\
\hline Age, mean (SD), y & $46.6(14.6)$ & $46.4(14.5)$ & $47.2(14.5)$ & $47.0(14.3)$ & $46.7(14.4)$ \\
\hline \multicolumn{6}{|l|}{ Comorbidity level (major ADGs) ${ }^{b}$} \\
\hline Low $(0-1), \%$ & 57.3 & 67.5 & 69.8 & 71.7 & 74.3 \\
\hline Medium (2-3), \% & 35.2 & 28.0 & 26.7 & 25.0 & 23.3 \\
\hline $\operatorname{High}(\geq 4), \%$ & 7.5 & 4.5 & 3.5 & 3.3 & 2.4 \\
\hline \multicolumn{6}{|l|}{ Ambulatory care use ${ }^{c}$} \\
\hline Physician visits, mean No. (SD) & $29.1(23.1)$ & $22.6(18.6)$ & $22.1(18.3)$ & $20.8(17.1)$ & $20.0(16.5)$ \\
\hline Usual physician index, mean $(S D)^{d}$ & $0.59(0.23)$ & $0.63(0.23)$ & $0.64(0.22)$ & $0.64(0.22)$ & $0.62(0.22)$ \\
\hline Received influenza vaccine, \% & 33.9 & 31.3 & 32.4 & 32.6 & 32.6 \\
\hline Referred to specialist, \% & 7.3 & 6.6 & 7.1 & 5.9 & 7.1 \\
\hline \multicolumn{6}{|l|}{ Usual physician characteristicse } \\
\hline Type, family physician, \% & 91.6 & 92.3 & 91.7 & 91.8 & 90.7 \\
\hline Payment, fee for service, \% & 96.6 & 97.1 & 97.6 & 97.8 & 97.7 \\
\hline Sex, male, \% & 80.9 & 74.3 & 73.7 & 72.3 & 70.3 \\
\hline \multicolumn{6}{|l|}{ Time practicing in Manitoba } \\
\hline $1-9 y$ & 27.9 & 24.4 & 21.5 & 21.8 & 21.9 \\
\hline $10-17 y$ & 27.9 & 24.5 & 26.3 & 24.8 & 22.7 \\
\hline$\geq 18$ y & 44.2 & 51.1 & 52.2 & 53.5 & 55.4 \\
\hline Training, international, \% & 41.0 & 39.0 & 38.0 & 36.5 & 35.2 \\
\hline Daily patient load, mean No. (SD) & $34.8(16.0)$ & $33.9(14.3)$ & $33.7(14.0)$ & $33.0(13.3)$ & $32.0(12.7)$ \\
\hline \multicolumn{6}{|l|}{ ADG $=$ aggregated diagnosis group.} \\
\hline \multicolumn{6}{|l|}{ Note: Data only available starting in 1991.} \\
\hline \multicolumn{6}{|c|}{$\begin{array}{l}\text { a All differences between groups were significant at } P<.05 \text { on analysis of variance or } \chi^{2} \text { analysis. } \\
\text { b Of } 8 \text { major ADGs during } 3 \text { years: ADG3, ADG4, ADG9, ADG11, ADG16, ADG22, ADG25, or ADG32. } \\
\text { ' For the } 3 \text {-year period before index hospitalization or median time to that event; 1-year period for influenza vaccine. } \\
\text { d Possible range: } 0 \text { to } 1.0 \text {. Higher values indicate greater continuity of care. } \\
\text { e At the patient level; for example, } 80.9 \% \text { of patients in } Q 1 \text { had a male usual physician. }\end{array}$} \\
\hline
\end{tabular}

with low-income patients more likely to be female and have a higher level of comorbidity. Although age differed significantly between groups, the differences were small and did not follow a clear pattern by income. These 3 variables are known to influence ACSC hospitalization rates. ${ }^{4,5,7,20,21}$ Adjusting for age and sex, and controlling for comorbidity, are therefore important when comparing ACSC hospitalization rates between groups. Indeed, comparing across models, we observed the largest decrease in effect size for SES after controlling for patient demographics (model B vs A). Nevertheless, income quintile remained a highly significant predictor of hospitalization, confirming that the association of SES with hospitalization was not solely due to demographic differences between groups.

We also found significant differences in ambulatory care use between income quintiles. As shown previously
Table 2. Socioeconomic Status as a Predictor of Obstructive Airway Disease-Related Hospitalization Across Models

\begin{tabular}{|c|c|c|c|c|}
\hline \multirow{2}{*}{$\begin{array}{l}\text { Income } \\
\text { Quintile }\end{array}$} & \multicolumn{4}{|c|}{ Odds Ratio (95\% Confidence Limit) } \\
\hline & Model A & Model B & Model C & Model D \\
\hline Q1 (lowest) & $3.72^{\mathrm{a}}(2.81,4.92)$ & $3.10^{\mathrm{a}}(2.33,4.13)$ & $3.15^{\mathrm{a}}(2.35,4.21)$ & $2.93^{\mathrm{a}}(2.19,3.93)$ \\
\hline Q2 & $2.61^{\mathrm{a}}(1.95,3.50)$ & $2.45^{\mathrm{a}}(1.82,3.30)$ & $2.61^{\mathrm{a}}(1.93,3.53)$ & $2.51^{\mathrm{a}}(1.86,3.40)$ \\
\hline Q3 & $1.70^{\mathrm{a}}(1.24,2.33)$ & $1.57^{\mathrm{a}}(1.14,2.16)$ & $1.60^{\mathrm{a}}(1.15,2.21)$ & $1.54^{\mathrm{a}}(1.11,2.13)$ \\
\hline Q4 & $1.38(0.99,1.91)$ & $1.33(0.95,1.85)$ & $1.43^{\mathrm{a}}(1.02,2.01)$ & $1.41^{\mathrm{a}}(1.01,1.98)$ \\
\hline Q5 (highest) ${ }^{\mathrm{b}}$ & 1.0 & 1.0 & 1.0 & 1.0 \\
\hline \multicolumn{5}{|c|}{$\begin{array}{l}\text { a } P<.05 . \\
\text { b Reference group for odds ratio calculation. }\end{array}$} \\
\hline \multicolumn{5}{|c|}{$\begin{array}{l}\text { Notes: model } A=\text { income quintile only; model } B=\text { income quintile + patient demographics; model } C=\text { income } \\
\text { quintile + patient demographics }+ \text { ambulatory care use; and model } D=\text { income quintile }+ \text { patient demograph- } \\
\text { ics + ambulatory care use + usual physician characteristics. }\end{array}$} \\
\hline
\end{tabular}


in Manitoba, ${ }_{1}^{11}$ patients from low-income areas had a greater number of physician visits than patients from high-income areas. The lowest SES group, Q1, also had the highest rate of influenza vaccination and specialist referrals, despite previous concerns about limited access to preventive care ${ }^{9,13}$ and specialist services ${ }^{1,10}$ in low-income areas leading to hospitalizations. A recent report from Canada has in fact shown that patients with an ACSC-related hospitalization are more likely to access primary care and specialist services, and to have a regular physician. ${ }^{20}$ Although the usual physician index was lowest in Q1, these patients also had the most physician visits. As the number of visits increases, the tendency to see different physicians also increases, regardless of income. ${ }^{22}$ Controlling for the number of visits or using different definitions of continuity, other studies have shown no effect of SES on continuity of care in Canada. ${ }^{10,22}$ Either way, controlling for continuity, as well as the other covariates related to ambulatory care use (model C vs B), resulted in very little change in the effect of SES as a predictor of hospitalization, and in fact boosted the odds ratio for Q4 vs Q5 from nonsignificant to significant. These results verify that in the context of universal health care, the link between SES and ACSC hospitalizations is not due to limited access to primary or specialist care, differences in preventive services such as vaccinations, or having a regular physician in low-income neighborhoods. Furthermore, appropriate vaccination and specialist consultation for at-risk patients relates to the quality of care they receive from their primary care clinician, suggesting that low-SES patients with obstructive airway disease do not end up in the hospital because of subpar ambulatory care.

Finally, we found significant differences between SES groups in usual physician characteristics, which are often used as surrogate markers of the quality of care they provide ${ }^{15}$ and were included to further explore the idea that in countries with universal health care, differences in quality, not access, may drive the inequity in ACSC hospitalizations. ${ }^{14}$ Relative to peers having high SES, lower-income patients were more likely to have a regular physician who was male, an international graduate, and less experienced, all traits that have been linked to poor performance or health outcomes, although the literature is inconsistent. ${ }^{7,15,23-26}$ We also found differences between groups in usual physician payment scheme, status as a family physician or specialist, and patient load, variables that have been shown to influence patient outcomes, including hospitalization risk. ${ }^{7,27-30}$

These differences between groups were marked enough to expect that physician characteristics could modulate the effect of SES. After adding usual physician characteristics to the final model, however, the overall effect size of income quintile and the individual odds ratios decreased only slightly, and SES remained a highly significant predictor of hospitalization.

The results of our analysis apply to the entire population of adults with obstructive airway disease in a major urban center with universal health care. Use of administrative data has limitations, however. Several of our measures of quality of care, namely, physician characteristics, were only surrogate markers. We did not have any data on physicians' adherence to guidelines, communication skills, or other aspects of the patientphysician relationship known to influence outcomes in obstructive airway disease. ${ }^{31}$ At the patient level, we could not measure a variety of personal health practices known to influence ACSC hospitalizations, including adherence to medication, ${ }^{32}$ alcohol use, and smoking. ${ }^{33}$ Given our focus on obstructive airway disease, smoking data may seem particularly important ${ }_{i}$ however, a previous study found that even after controlling for smoking, individuals from the lowest SES group were still 3 times more likely to be hospitalized for COPD than those in the highest SES group, ${ }^{6}$ a result nearly identical to ours. Although we used comorbidity level as a proxy of overall health status, ${ }^{20}$ we lacked an individual-level measure of the severity of obstructive airway disease for each patient. Finally, the generalizability of the study may be limited as it is from a single Canadian city. Two previous studies have indicated that disease severity may explain much of the SES relationship with obstructive airway disease hospitalizations. ${ }^{34,35}$ Besides being carried out in the United States, which does not have universal health care, those studies had considerable methodologic differences relative to ours, including smaller sample sizes, lack of individuals from the extremes of income, a restricted age range, and the inclusion of emergency department visits as hospitalizations. Data on disease severity would be useful, but it remains to be proven that it would fully explain the inequity in hospitalizations we observed.

Our study has important policy implications. The results suggest that it may be factors outside of direct contact with the health care system, outside of the physician's office, that lead to the inequity in obstructive airway disease hospitalizations. We have demonstrated that neither differences in the type of care nor the physicians providing this care are driving the disadvantaged to be hospitalized. This study reminds us of the importance of the social determinants of health, even when discussing a concept often thought of as a marker of the performance of a health care system, such as ACSCs. In countries with universal health care, such as Canada, the reduction of preventable hospital admissions due to obstructive airway disease and other ACSCs will require that programs and policies address the poverty associated with poor outcomes. 
To read or post commentaries in response to this article, see it online at http://www.annfammed.org/content/12/5/402.

Key words: ambulatory care; asthma; avoidable hospitalizations; chronic obstructive pulmonary disease; health status disparities; respiratory disease; social determinants of health

Submitted January 3, 2014; submitted, revised, April 28, 2014; accepted May 20, 2014.

Acknowledgments: We acknowledge the MCHP for use of data contained in the Population Health Research Data Repository, housed at MCHP, University of Manitoba.

Funding support: This work was supported by a grant from the Canadian Institutes of Health Research. A. Katz acknowledges the support of the Manitoba Health Research Council and the Heart and Stroke Foundation for his Research Chair in Primary Prevention (2013-2018).

Disclaimer: The results and conclusions of this study are those of the authors and no official endorsement by MCHP or Manitoba Health is intended or inferred.

\section{References}

1. Billings J, Zeitel L, Lukomnik J, Carey TS, Blank AE, Newman L. Impact of socioeconomic status on hospital use in New York City. Health Aff (Millwood). 1993;12(1):162-173.

2. Brown AD, Goldacre MJ, Hicks N, et al. Hospitalization for ambulatory care-sensitive conditions: a method for comparative access and quality studies using routinely collected statistics. Can J Public Health. 2001;92(2):155-159.

3. Sanchez M, Vellanky S, Herring J, Liang J, Jia H. Variations in Canadian rates of hospitalization for ambulatory care sensitive conditions. Healthc Q. 2008;11(4):20-22.

4. Shi L, Samuels ME, Pease M, Bailey WP, Corley EH. Patient characteristics associated with hospitalizations for ambulatory care sensitive conditions in South Carolina. South Med J. 1999;92(10):989-998.

5. O'Neil SS, Lake T, Merrill A, Wilson A, Mann DA, Bartnyska LM. Racial disparities in hospitalizations for ambulatory care-sensitive conditions. Am J Prev Med. 2010;38(4):381-388.

6. Prescott $E$, Lange $P$, Vestbo J. Socioeconomic status, lung function and admission to hospital for COPD: results from the Copenhagen City Heart Study. Eur Respir J. 1999;13(5):1109-1114.

7. O'Malley AS, Pham HH, Schrag D, Wu B, Bach PB. Potentially avoidable hospitalizations for COPD and pneumonia: the role of physician and practice characteristics. Med Care. 2007;45(6):562-570.

8. Balogh RS, Ouellette-Kuntz H, Brownell M, Colantonio A. Factors associated with hospitalisations for ambulatory care-sensitive conditions among persons with an intellectual disability: a publicly insured population perspective. J Intellect Disabil Res. 2013;57(3):226-239.

9. Disano J, Goulet J, Muhajarine N, Neudorf C, Harvey J. Socialeconomic status and rates of hospital admission for chronic disease in urban Canada. Can Nurse. 2010;106(1):24-29.

10. Booth GL, Hux JE. Relationship between avoidable hospitalizations for diabetes mellitus and income level. Arch Intern Med. 2003;163(1): 101-106.

11. Roos LL, Walld R, Uhanova J, Bond R. Physician visits, hospitalizations, and socioeconomic status: ambulatory care sensitive conditions in a Canadian setting. Health Serv Res. 2005;40(4):1167-1185.

12. Ansari Z, Laditka JN, Laditka SB. Access to health care and hospitalization for ambulatory care sensitive conditions. Med Care Res Rev. 2006;63(6):719-741.

13. Agabiti N, Pirani M, Schifano P, et al; Italian Study Group on Inequalities in Health Care. Income level and chronic ambulatory care sensitive conditions in adults: a multicity population-based study in Italy. BMC Public Health. 2009;9:457.

14. Purdy S, Griffin T, Salisbury C, Sharp D. Ambulatory care sensitive conditions: terminology and disease coding need to be more specific to aid policy makers and clinicians. Public Health. 2009;123(2): 169-173.
15. Reid RO, Friedberg MW, Adams JL, McGlynn EA, Mehrotra A. Associations between physician characteristics and quality of care. Arch Intern Med. 2010;170(16):1442-1449.

16. Manfreda J, Becker AB, Wang PZ, Roos LL, Anthonisen NR. Trends in physician-diagnosed asthma prevalence in Manitoba between 1980 and 1990. Chest. 1993;103(1):151-157.

17. Manitoba Centre for Health Policy. Population Health Research Data Repository, Administrative Health Databases. July 15, 2011. http://www.umanitoba.ca/faculties/medicine/units/community_ health_sciences_departmental_units/mchp/resources/repository/ health_admin.html. Accessed July 19, 2013.

18. Roos NP, Mustard CA. Variation in health and health care use by socioeconomic status in Winnipeg, Canada: does the system work well? Yes and no. Milbank Q. 1997;75(1):89-111.

19. Phan K, Brown SR. Decreased continuity in a residency clinic: a consequence of open access scheduling. Fam Med. 2009;41(1):46-50.

20. Sanmartin C, Khan S, the LHAD research team. Health Research Working Paper Series - Hospitalizations for Ambulatory Care Sensitive Conditions (ACSC): The Factors That Matter, no. 7. Statistics Canada. June 30, 2011. http://www5.statcan.gc.ca/bsolc/olc- cel/olc-cel?catno= 82-622-XIE2011007Elang=eng\#formatdisp. Accessed July 19, 2013.

21. Aubas C, Bourdin A, Aubas P, et al. Role of comorbid conditions in asthma hospitalizations in the south of France. Allergy. 2013;68(5): 637-643.

22. Erzen D, Carriere KC, Dik N, et al. Income level and asthma prevalence and care patterns. Am J Respir Crit Care Med. 1997;155(3): 1060-1065.

23. Southern WN, Bellin EY, Arnsten JH. Longer lengths of stay and higher risk of mortality among inpatients of physicians with more years in practice. Am J Med. 2011;124(9):868-874.

24. Davidson W, Molloy DW, Bédard M. Physician characteristics and prescribing for elderly people in New Brunswick: relation to patient outcomes. CMAJ. 1995;152(8):1227-1234.

25. Jerant A, Bertakis KD, Fenton JJ, Franks P. Gender of physician as the usual source of care and patient health care utilization and mortality. J Am Board Fam Med. 2013;26(2):138-148.

26. Norcini JJ, Boulet JR, Dauphinee WD, Opalek A, Krantz ID, Anderson ST. Evaluating the quality of care provided by graduates of international medical schools. Health Aff (Millwood). 2010;29(8):1461-1468.

27. Liddy C, Singh J, Hogg W, Dahrouge S, Taljaard M. Comparison of primary care models in the prevention of cardiovascular diseasea cross sectional study. BMC Fam Pract. 2011;12:114.

28. Szucs TD, Anderhub HP, Rutishauser M. Determinants of health care costs and patterns of care of asthmatic patients in Switzerland. Schweiz Med Wochenschr. 2000;130(9):305-313.

29. Saxena S, George J, Barber J, Fitzpatrick J, Majeed A. Association of population and practice factors with potentially avoidable admission rates for chronic diseases in London: cross sectional analysis. J R Soc Med. 2006;99(2):81-89.

30. Rizza P, Bianco A, Pavia M, Angelillo IF. Preventable hospitalization and access to primary health care in an area of Southern Italy. BMC Health Serv Res. 2007;7:134.

31. Gillissen A, Wirtz $H$, Juergens $U$. Patient and physician factors contributing to poor outcomes in patients with asthma and COPD. Dis Manag Health Outcomes. 2007;15(6):355-376.

32. Simoni-Wastila L, Wei YJ, Qian J, et al. Association of chronic obstructive pulmonary disease maintenance medication adherence with all-cause hospitalization and spending in a Medicare population. Am J Geriatr Pharmacother. 2012;10(3):201-210.

33. Chew RB, Bryson CL, Au DH, Maciejewski ML, Bradley KA. Are smoking and alcohol misuse associated with subsequent hospitalizations for ambulatory care sensitive conditions? J Behav Health Serv Res. 2011;38(1):3-15.

34. Eisner MD, Katz PP, Yelin EH, Shiboski SC, Blanc PD. Risk factors for hospitalization among adults with asthma: the influence of sociodemographic factors and asthma severity. Respir Res. 2001;2(1):53-60.

35. Eisner MD, Blanc PD, Omachi TA, et al. Socioeconomic status, race and COPD health outcomes. J Epidemiol Community Health. 2011; 65(1):26-34. 